\title{
Machado de Assis, o Crítico da Imprensa: o jornal entre palmas e piparotes
}

Marcos Fabrício Lopes da Silva

Resumo

\begin{abstract}
Esta dissertação tem como objetivo analisar as crônicas de Machado de Assis publicadas em jornais na segunda metade do século XIX, a fim de destacar a atuação do jornalista/cronista como admirador da imprensa e crítico do jornal. As ocasiões em que o nosso escritor aplaude a imprensa equivalem aos momentos de "palmas". Os "piparotes", por sua vez, representam a reprovação de Machado de Assis frente aos deslizes de caráter ético e editorial, cometidos pelos jornais.
\end{abstract}

Palavras-chave: Machado de Assis. Crônica. Jornal. Crítico da imprensa.

Pretendi com este estudo expor e discutir a crítica da imprensa exercida pelo jornalista Machado de Assis em suas crônicas publicadas nos mais variados jornais entre o Segundo Reinado e o início da República. Entre "palmas" e "piparotes", nosso cronista se posicionou diante do juízo formulado a partir da prática jornalística da segunda metade do século XIX. Ora Machado se empolgava com a dialética do esclarecimento prometida pelo ideal de jornalismo, ora o cronista, mais experiente na prática jornalística, reprovava os abusos éticos e editoriais que levavam os jornais a adotar uma filosofia sensacionalista e uma mentalidade mais conservadora no intuito de enaltecer os aspectos hegemônicos de uma sociedade escravocrata e não acostumada ao clima democrático sustentado pela liberdade de expressão.

Reconhecido como romancista notável e grande contista, faltam mais estudos a respeito da dramaturgia, das poesias e das crônicas produzidas por Machado de Assis. Analisando a produção jornalístico-literária do nosso escritor, o papel da imprensa, assim como seus limites éticos que buscam o equilíbrio entre a liberdade de informar e a responsabilidade no exercício deste ofício, aparecem com bastante freqüência como tema, levando-me a afirmar que Machado de Assis foi um destacado crítico da imprensa. Como ele exercia esta crítica?

Kritos em grego refere-se ao juiz, ao árbitro. Antes do Iluminismo o conceito de crítica estava relacionado com o de censura. Kant trouxe a noção de criticismo como ferramenta na busca do conhecimento. Para Machado, a crítica da imprensa não se restringe a apontar os erros desta entidade noticiosa. $O$ cronista pretende sobretudo indicar caminhos e disseminar juízos por acreditar na capacidade de aprimoramento do ofício jornalístico. Machado ressaltou que assinalar os equívocos da imprensa não é 
uma forma de invalidá-la e sim de afirmá-la. Como "república do pensamento" (MACHADO, 1997, p. 945), o jornalismo deve remediar não só as crises alheias, como também os próprios "pecados" editoriais. Se o jovem Machado aplaude a luta da imprensa para legitimar o princípio universal dos direitos, o mesmo, mais experiente, perceberá que a reforma pelo jornal passa primeiro por uma reforma no jornal, que ainda se encontrava, no Brasil, comprometido com a noção de interesses particulares.

Nas crônicas intituladas "O jornal e o livro", "O folhetinista" e "A reforma de jornal", publicadas em 1859, o jovem Machado se mostrava um convicto entusiasta do jornalismo. Acreditando no poder revolucionário da imprensa como agente capaz de trazer as reformas tão necessárias a um país marcado pela escravidão, pelo analfabetismo e por uma rede nefasta de privilégios provenientes de uma sociedade estamental, Machado de Assis vai elaborar uma propaganda positiva do jornalismo, posicionando-o como a "verdadeira forma da república do pensamento". Atribuindo-lhe uma missão repleta de responsabilidade social, o cronista entende o jornalismo como um serviço público capaz de transformar a curiosidade individual em bem coletivo. Desta forma, surge a figura do jornalista como um ser destemido, uma espécie de super-herói, que não mede esforços para trazer a verdade dos fatos à tona. O saber, antes acumulado nas mãos da aristocracia, ganharia as ruas pela ação da imprensa. Devido ao circuito restrito tanto no aspecto produtivo, levando-se em conta o monólogo do escritor e a sua solidão intelectual, quanto no aspecto de consumo, considerando os poucos leitores que têm condições financeiras e intelectuais para comprar e ler uma obra, o livro é percebido pelo jovem cronista como um instrumento aristocrático, que não atende mais a uma "inquietação" da modernidade, melhor comportada pelo jornal. Este apresenta um espectro de audiência mais ampliado, um suporte que admitia a participação de vários agentes sociais na construção de um discurso mais pluralista, e uma escala de tempo mais dinâmica. Diante desses fatores, Machado de Assis afirma até que o jornal é uma "literatura quotidiana", uma "reprodução diária do espírito do povo" (1997, p. 946).

Apropriando-se da associação do folhetinista com o beija-flor, construída por José de Alencar (uma referência crucial para a literatura e o jornalismo machadiano), nosso cronista assimila esta metáfora como estilo na medida em que vai visitar - como se fosse um colibri - vários assuntos, para dali tirar o seu sustento e a matéria para as crônicas que buscam destacar o encoberto, na contramão de assuntos altamente "consagrados" e de apelo sensacionalista. A "fusão do útil e do fútil" (MACHADO, 1997, p. 959) faz brotar a arte da desconversa que marca a crônica de Machado de Assis como uma sobremesa que vai rebater o jantar, conforme ele próprio um dia definiu. A crônica não é o prato principal, mas rouba a cena do banquete que alimenta o pobre espírito que resiste à dança macabra das coisas sólidas.

O sabor da opinião em detrimento do mero conhecer promovido superficialmente pela informação é a tônica do jornalismo desenvolvido por Machado de Assis. Para ele, - cronista deve registrar o cotidiano, tornando explícitas as suas marcas interpretativas e discutindo com os próprios leitores, enquanto narra episódios, o seu próprio método de contar histórias, ou seja, o fazer jornalístico. Machado esquiva-se da impessoalidade para destacar a importância da subjetividade do informante que não teme tomar posição sobre os fatos e assumir perante ao público sua parcialidade.

O jornalismo como grande veículo do espírito moderno e elevado à categoria de "república do pensamento" por Machado de Assis passa a ser desmistificado por ele mesmo, quando o jornal se afasta do seu papel de instruir o leitor, informando-o adequadamente. Aquele que destacou, na juventude, a importância fundamental do 
jornalismo na formação de uma esfera pública capaz de submeter os pólos do poder ao olhar atento da sociedade civil, assistiu, na maturidade, ao colapso dessa visão e percebeu o fracasso do jornalismo exercido no Brasil como Quarto Poder. Assim, Machado se viu obrigado a pensar na estruturação de um outro poder - o quinto que tivesse como função central a fiscalização do poder da imprensa.

Poder-se-ia então afirmar que o escritor foi um atento crítico da imprensa de seu tempo e, talvez, até mesmo, um ombudsman. Conforme Jairo Faria Mendes (2002), o ombudsman critica a postura editorial do veículo em que trabalha, assim como dos demais jornais, além de prestar serviços de ouvidoria, encarregando-se de atuar como representante dos leitores no jornal. Nas crônicas que compõem o corpus desse trabalho, não há declarações explícitas do escritor afirmando que tenha feito uma crítica à imprensa com base na escuta de alguma queixa do leitor, ou através de carta deste dirigida ao jornal em que atuava. O desconhecimento, até agora, dessa prova cabal, me impede de afirmar, com exatidão, que Machado de Assis tenha sido, de fato, um ombudsman.

Diante da ferrenha crítica do escritor em relação à prática jornalística, é possível cogitar a hipótese de que ele tenha recebido reclamações, sugestões e elogios dos seus leitores em relação aos jornais nos quais trabalhou. Pode-se pensar que Machado de Assis reunia as críticas feitas pela sociedade no tocante ao comportamento editorial dos periódicos, a suas próprias observações e investigações sobre o fazer jornalístico, o que pode ter acontecido, por exemplo, em seus passeios de bond ou no contato com os leitores na Rua do Ouvidor. Mário de Alencar, amigo de Machado de Assis, registrou, da seguinte forma, o cotidiano do cronista: "pela manhã, bebido o café, escrevia; depois do banho, lia os seus autores passeando pelo gabinete. Finda a tarefa diária, entregava-se aos jornais antes e depois do almoço e no bonde" (ALENCAR apud WERNECK, 1994, p. 53).

Cabe ainda informar que todo ombudsman é um crítico da imprensa, mas nem todo crítico da imprensa é um ombudsman. O crítico da imprensa difere do ombudsman, por não ser necessariamente um ouvidor dos leitores e por poder avaliar o desempenho da imprensa atuando em outro setor do jornal que não seja o de ouvidoria, como em veículos alternativos, que buscam especificamente radiografar a atuação dos jornais. Tanto o ombudsman como o crítico da imprensa costumam ser considerados "malditos", porque existiria "um temor da mídia em se abrir para a crítica" (MENDES, 2002, p. 14). Acontece que a atuação desses profissionais, como foi o caso de Machado de Assis, permite que o próprio jornalista faça uma reflexão permanente do seu exercício profissional, se recorde que é falível, e que seus erros afetam a sociedade inteira. Na opinião de Geraldo Albarrán de Alba, "o ombudsman do leitor não é outra coisa que a consciência do jornalista" (2002, p. 12). Já o bom crítico da imprensa, recomenda Alberto Dines (1982), deve focalizar desempenhos ou comportamentos dos jornais e dos jornalistas enquadrando a estrutura que cria, estimula e orienta tais desempenhos ou comportamentos.

No ensaio "'Media criticism'- um espaço mal-dito", Dines observa que o autêntico crítico da imprensa deve se posicionar "contra a maré", atingindo a essência da estrutura paternalista e autoritária que contamina os jornais. Segundo Dines, Lima Barreto teria sido o precursor da crítica à imprensa no Brasil com o livro Recordações do escrivão Isaías Caminha, de 1909. Pela língua afiada e pelo estilo destemido, a obra e o autor foram boicotados, respectivamente, pela crítica e pelos grandes meios de comunicação da época. Alvo do preconceito racial, social e literário, visto que era negro 
e pobre, o autor sofreu mais um golpe: as portas das folhas públicas encontravam-se fechadas para ele, assim como as portas da Academia Brasileira de Letras.

Porém, antes de Lima Barreto, Machado de Assis já executava a função de crítico da imprensa desde o início de sua carreira, a partir de "A reforma pelo jornal", publicado em 23 de outubro de 1859. Neste texto ele fez a seguinte declaração: "é verdade que o jornal aqui não está à altura da sua missão" (1997, p. 964). Cinqüenta anos antes de Recordações do escrivão Isaías Caminha, o cronista já exercia o seu papel de fiscal ético e social, driblando os desconfortos da marginalização que poderiam ter sido impostos pelos mandarins dos jornais em que trabalhava. Enquanto Lima Barreto teve que se contentar com a imprensa alternativa para publicar seus posicionamentos mais críticos em relação à sociedade brasileira e à própria atividade jornalística, Machado de Assis conseguiu realizar a crítica da imprensa nos grandes veículos de comunicação, estando a serviço deles. Esta proeza por parte do escritor se deve, a meu ver, ao habilidoso emprego da ironia como refinamento da expressão, pela lúcida consciência do horizonte de expectativas do leitor (em sua esmagadora maioria, a classe senhorial) e do fait divers como disfarce, como tática dispersiva, na condução das suas análises críticas em relação à imprensa.

Desta feita, Machado se encolhe feito um caramujo não só quando assume uma postura de recolhimento interior, exigida pela atividade de reflexão ao analisar o choque entre os estímulos externos e os valores internos, mas também para se enquadrar, disfarçadamente, dentro de uma concha, a fim de satisfazer os gostos dos donos do poder e dos jornais. Mas é ele quem também coloca a cabeça para fora da concha e se expõe ao realizar um jornalismo que vai de encontro ao sistema tradicional. É um movimento perspicaz, que vai às raias de um paradoxo no primeiro momento. Em "O cronista e a semana", de 16/09/1894, Machado incorpora por exemplo a figura de um jornalista sensacionalista, não porque comunga deste parâmetro editorial, como nos faz crer uma leitura rasteira, mas sim por preferir "entrar na pele" e melhor denunciar os valores daqueles que promovem um jornalismo com sede de violência e encantado pela tragédia. Trata-se de uma oposição sofisticada, fruto de uma monumental ironia. Agindo assim, ele desmonta o sensacionalismo, camuflado na roupagem desse estilo. Ele não se confunde, apenas se fantasia. E, na hora certa, manifesta-se na ação de sair do encolhimento e expor os vícios daquela estrutura noticiosa.

$\mathrm{Na}$ literatura de Machado de Assis prevalece a ironia pautada pela ambigüidade (recurso expressivo de mão dupla), na qual a primeira camada textual é permeada pela visibilidade do modus vivendi do estamento senhorial. Acontece que se mergulharmos nas profundezas da expressão literária machadiana, driblando a tática dispersiva que Ihe convinha, nos depararemos com uma "voz autoral" que não compartilha dos hábitos hegemônicos, tecendo-Ihes uma crítica aguçada. Por sua vez, no jornalismo praticado por Machado de Assis, percebemos um sujeito que, ao afirmar suas posições de maneira opinativa na imprensa de seu tempo, "toma partido", alimentando-se muito mais de uma ironia empenhada do que propriamente de uma ironia ambígua. No caso da crítica à imprensa sensacionalista, o jornalista Machado de Assis protesta contra os efeitos artificiais da "semana rica", a favor dos encantos da "semana pobre", com o objetivo de apontar um caminho ético e de qualidade editorial para a atividade jornalística.

Ao preferir as "semanas pobres", Machado de Assis denuncia o apelo sensacional das "emanas ricas" - vistas como aquelas que preferem especular sobre a tragédia de um acidente que oferece à população o espetáculo de "pernas esmigalhadas, ventres 
estripados, crânios arrebentados, lágrimas, gritos, viúvas, órfãos, angústias, desesperos" que rende "assunto fértil para três dias" e "comoções públicas".

O sensacionalismo é o principal alvo de crítica de Machado de Assis a um tipo de imprensa que adota esta linha editorial. No primeiro momento, em 1885, o cronista oferece, como remédio de combate à marginalidade, que a imprensa não destaque em suas manchetes o criminoso e os seus feitos. Graças ao "erotismo de publicidade", o capoeira recorre às navalhas certo de que o jornal irá noticiar aquela prática. Aos criminosos, receita Machado, a indiferença dos jornais. Já em 1894, seu olhar crítico sobre o fazer jornalístico manifesta-se na designação das "semanas ricas" e as "semanas pobres", configurando assim, uma visão mais sofisticada a respeito do sensacionalismo. Além de considerar tal fenômeno como atrativo comercial tão caro à promoção do consumo dos jornais e como elemento propagador da violência, influenciando pessoas a seguirem o caminho da fama obtida por meios ilegais pelos "capoeiras", Machado admite compreender o sensacionalismo como forma de atender à necessidade coletiva da "pulsão de morte", na medida em que serve como "escape" à agressividade natural do ser humano.

O jornalismo foi uma tribuna ampliada para o envolvimento de Machado de Assis com as questões político-sociais do seu tempo, utilizando a imprensa como recurso metonímico para criticar uma sociedade oportunista e que vivia de um liberalismo de fachada. Em "História de quinze dias", de 15/08/1876, Machado concluiu argutamente que era falacioso pensar em opinião pública nacional formada pelo saber de todos os brasileiros. $\mathrm{O}$ alto índice de analfabetismo - 84\% - diagnosticado pelo Império ofereceu margem para que o cronista afirmasse categoricamente que "a opinião pública é uma metáfora sem base" (ASSIS, 1997, p. 345). Na crônica de "Balas de Estalo", publicada em 17/02/1885, Machado denunciou corajosamente a censura policial às manifestações dos "barrados no baile" que praticavam o entrudo, enquanto a grande imprensa não noticiava este episódio e mascarava o clima tenso com notícias inventadas, afirmando que o carnaval foi bem animado e livre de violência. Em "Notas Semanais", de 1\%/09/1878, Machado destacou a arrogância de veículos de comunicação (Revue des Deux Mondes e Figaro), que não admitiam os seus próprios erros publicamente. Denunciou um dos maiores genocídios midiáticos já ocorridos no Brasil, que foi a perseguição declarada da grande imprensa ao arraial de Canudos, especialmente ao líder Antonio Conselheiro. Alimentando-se de boatos e telegramas oficiais, a imprensa endossou aquelas versões e sem provas estigmatizou Conselheiro como um "baderneiro", "inimigo número um da República", "fanático" e "facínora". Em "A Semana", de 31/01/1897, Machado de Assis ficou desapontado com esta prática e recomendou que a imprensa ouvisse o outro lado da história e fosse in loco acompanhar e divulgar as verdadeiras motivações daquele movimento social que prometia reinventar o sertão. Na época, não era costume dos jornais enviar correspondentes para os locais das rebeliões. Mas, apesar disso, Machado reivindicou a ida de repórteres que trouxessem informações direito do arraial de Canudos e tornassem públicas as declarações de Antonio Conselheiro e de seu povo, descartando a manipulação ideológica dos telegramas e de outras artimanhas oficiais. Na Gazeta de Holanda, de 27/09/1887, o cronista Machado de Assis teve a audácia de dar voz, em uma de suas crônicas, a um escravo de ganho, Pai Silvério. Este era visto por Machado como sujeito politizado e valiosa fonte de informação, por se tratar do principal alvo nos debates que antecederam a Abolição da Escravatura. Conforme nos mostra o conto machadiano "Pai contra mãe", a imprensa, reforçando a mentalidade escravocrata da época, só destacava o escravo nos anúncios publicitários como objeto de consumo ou 
como fonte de recompensa para aquele que o entregasse ao senhor. Estes textos mostram que Machado de Assis, como escritor afro-descendente, não foi indiferente ao drama dos seus semelhantes.

Um objeto que sintetizaria bem a relação entre Machado de Assis e a imprensa é o pêndulo. Trata-se de um corpo móvel (a crítica do autor) em torno de um ponto fixo (a imprensa) e que oscila (entre as "palmas" entusiasmadas, sinalizando para as glórias do jornalismo, e os "piparotes", em nome da repreensão aos abusos de poder da imprensa, que atropelavam os limites éticos) sob a ação do próprio peso (a imprensa como quarto poder, ou para utilizar a definição do cronista, como "república do pensamento").

Entre palmas e piparotes, Machado de Assis realizou, à sua maneira, um fazer jornalístico marcado pela metalinguagem e pela reflexão crítica acerca do ofício, práticas que o tornam, além de excepcional romancista e cronista, um exímio crítico da imprensa brasileira do século XIX.

Abstract

This dissertation aims to analyze Machado de Assis' chronicles of the late XIX century, in order to point out his work as a journalist/chronicler as a critique and an admirer. The "palmas" ("applause") moments are related to his constructive criticism to the press. Also according to Machado de Assis, the "piparotes" in the other hand, stand for his reproval of the editorial and ethics flaws committed by newspapers.

Key words: Machado de Assis. Chronicle. Newspaper. Press critique.

Referências

ALBA, Geraldo Albarrán de. Prefácio. In: MENDES, Jairo Faria. $O$ ombudsman e o leitor. Belo Horizonte: O Lutador, 2002.

CARDOSO, Marília Rothier. Gazeta de bruxo. Tese (Doutorado em Literaturas de Língua Portuguesa) - Departamento de Letras, Pontifícia Universidade Católica do Rio de Janeiro, Rio de Janeiro, 1990. $490 \mathrm{f}$.

DINES, Alberto. "Media criticism" - um espaço mal-dito. In: SILVA, Carlos Eduardo Lins da (Coord.). Comunicação, hegemonia e contra-informação. São Paulo: Cortez; Intercom, 1982.

DUARTE, Lélia Parreira. Ironia, humor e fingimento literário. In: Cadernos de pesquisa do Napq - FALE/UFMG, Belo Horizonte, $\mathrm{n}$. 15, fev. 1994.

GALVÃO, Walnice Nogueira. No calor da hora: a guerra de Canudos nos jornais, 4. expedição. 2. ed. São Paulo: Ática, 1977.

GLEDSON, John. Machado de Assis: ficção e história. Tradução de Sônia Coutinho. Rio de Janeiro: Paz e Terra, 1986.

GRANJA, Lúcia. Machado de Assis, escritor em formação (à roda dos jornais). Campinas: Mercado das Letras; São Paulo: Fapesp, 2000. 
GUIMARÃES, Hélio de Seixas. Os leitores de Machado de Assis: o romance machadiano e o público de literatura no século 19. São Paulo: Nankin Editorial; EDUSP, 2004.

ASSIS, Machado de. Crônica. In: COUTINHO, Afrânio (Org.). Obra completa. Rio de Janeiro: Nova Aguilar, 1997, v. 3.

ASSIS, Machado de. Pai contra mãe. In: COUTINHO, Afrânio (Org.). Obra completa. Rio de Janeiro: Nova Aguilar, 1997, v. 2.

MENDES, Jairo Faria. O ombudsman e o leitor. Belo Horizonte: $O$ Lutador, 2002.

MORIN, Edgar. Cultura de massas no século $X X$ : o espírito do tempo. Rio de Janeiro: Forense Universitária, 1977.

PEREIRA, Wellington. Machado de Assis: discurso moderno em crônicas de Fin-de-Siècle; As idéias de época nas crônicas de Machado de Assis. In: Crônica: arte do útil e do fútil. João Pessoa: Idéia, 1994.

SCHWARZ, Roberto. Um mestre na periferia do capitalismo. 4. ed. São Paulo: Duas Cidades; Editora 34, 2000a.

SCHWARZ, Roberto. Ao vencedor as batatas: forma literária e processo social nos inícios do romance brasileiro. 5. ed. São Paulo: Duas Cidades; Editora 34, 2000b.

WERNECK, Maria Helena. O homem encadernado: as escritas das biografias de Machado de Assis. Tese (Doutorado em Literatura Brasileira) - Coordenação dos Cursos de Pós-Graduação em Letras, Universidade Federal do Rio de Janeiro, Rio de Janeiro, RJ. 1994. $361 \mathrm{f}$ 